\title{
Analisis Segmen Pasar Produk Handphone Berbasis Android di Lingkungan Mahasiswa di Banjarmasin
}

\author{
Abul Hasan Asy'ari ${ }^{1}$, Arief Noviarakhman Zagladi ${ }^{2}$ \\ ${ }^{12}$ Sekolah Tinggi Ilmu Ekonomi Pancasetia \\ Email : a_zagladi@yahoo.com
}

\begin{abstract}
This study aims to determine and analyze the market segment of android-based mobile users on college students in Banjarmasin. Sample used are 140 college Student. The variables used as a basis for segmentation are product attribute variables including indicators of quality, price, performance, durability, reliability, brand image, features, design, model, specifications, capacity, warranty and aesthetics. The analytical tool used is the K-Mean Cluster Analysis. The results showed that Cluster 1 is respondents who are concerned with price, performance, durability, features, specifications and warranty attributes. This cluster is named "Performance Cluster". Cluster 2 is the respondent who is concerned with all the attributes except the guarantee. This cluster is named "Product Cluster". Cluster 3 is respondents who are concerned with the attributes of features, models, capacities. This cluster is named "Cluster of Excellence"
\end{abstract}

Keywords : market segment, quality, price, performance, durability, reliability, brand image, features, design, model, specifications, capacity, warranty and aesthetics

Abstrak

Penelitian ini bertujuan untuk mengetahui dan menganalisis segmen pasar pengguna ponsel berbasis android pada mahasiswa di Banjarmasin. Sampel yang digunakan sebanyak 140 mahasiswa. Variabel-variabel yang digunakan sebagai dasar segementasi adalah variabel atribut produk meliputi indikator kualitas, harga, kinerja, daya tahan, kehandalan, citra merek, fitur, desain, model, spesifikasi, kapasitas, garansi dan estetika. Alat analisis yang digunakan adalah Analisis K- Mean Cluster. Hasil penelitian menunjukkan bahwa Klaster 1 adalah responden yang mementingkan atribut harga, kinerja, daya tahan, fitur, spesifikasi, dan garansi. Klaster ini diberi nama "Klaster Kinerja". Klaster 2 adalah responden yang mementingkan semua atribut kecuali garansi. Klaster ini diberi nama "Klaster Produk". Klaster 3 adalah responden yang mementingkan atribut fitur, model, kapasitas. Klaster ini diberi nama "Klaster Keunggulan".

Kata Kunci : Kualitas Makanan, Perceived Value, Kepuasan Konsumen.

(C) 2020 Jurnal Riset Inspirasi Manajemen dan Kewirausahaan

\section{PENDAHULUAN}

Dewasa ini pertumbuhan pengguna handphone meningkat pesat, hampir sedikit sekali masyarakat yang belum memiliki handphone. Handphone layaknya sebuah kebutuhan primer seperti halnya sandang, papan, dan pangan yang mau tidak mau harus dipenuhi oleh setiap orang. Masyarakat modern yang dicirikan dengan kesibukan yang sangat padat sehingga membuat waktu terasa singkat dan tidak cukup untuk bisa menyelesaikan semua pekerjaan dan aktivitas yang dilakukan, namun hal tersebut dapat diatasi dengan terciptanya teknologi handphone yang kemudian menjadi cikal bakal terciptanya ponsel pintar atau smartphone.

Begitu besarnya manfaat smartphone diera sekarang sehingga kebutuhan smartphone dapat disejajarkan dengan kebutuhan primer adalah karena manfaat smartphone itu sendiri bagi penggunanya sangatlah besar meliputi, Pertama, ketika ingin menghubungi keluarga, pasangan, sahabat, hingga klien dan rekan kerja yang berada jauh dari kita, tentu smartphone kita butuhkan untuk menelepon, mengiriman pesan, email, sms dan chatting kepada mereka. Tentunya hal ini membuat kita bisa berkomunikasi secara mudah apalagi untuk urusan pekerjaan yang selalu mengutamakan komunikasi di dalamnya. Kedua, mendapatkan informasi dan berkomunikasi dengan orang lain secara cepat. Berkat hadirnya internet, kini kita bisa mendapatkan informasi seperti berita terkini secara lebih cepat dan akurat. Bahkan suatu berita dapat kita ketahui hanya berjarak dari satu jam setelah kejadian tersebut telah terjadi. Tak hanya itu saja, berkat hadirnya media sosial seperti Facebook, Twitter, dan Instagram, kita memiliki kesempatan untuk mengetahui kabar terbaru sahabat, teman, dan orang-orang yang kita kenal. Bahkan kita juga bisa berkenalan dengan orang lain dan mendapatkan ilmu baru lewat sosial media. 
Ketiga, alat fotografi andalan. Memotret sebuah momen dan menjadikannya sebuah kenangan yang tak terlupakan adalah keharusan untuk diri kita. Berkat adanya smartphone, kebutuhan ini menjadi terpecahkan. foto yang dihasilkan pun terlihat bagus dan terpenting mempermudah dirimu dalam mengabadikan setiap momen penting yang ada. Keempat, memberikan hiburan. Mau membaca buku, menonton video, atau bermain game. Semuanya bisa kita lakukan lewat smartphone. Dan yang terpenting, kita bisa melakukannya di mana saja dan kapan saja kita berada. Kelima, pergi kemana saja secara mudah. Selalu tersesat ketika berpergian? Smartphone tentu saja jadi penyelamat! Berkat hadirnya GPS dan aplikasi transportasi online, kita tak perlu khawatir untuk pergi kemana pun walaupun tak tahu secara pasti lokasi tujuan kita. Dengan semua manfaat tersebut wajarlah kalau dikatakan bahwa smartphone adalah sebuah kebutuhan pokok bagi masyarakat modern karena manfaatnya yang besar dalam menunjang kehidupan masyarakat.

Teknologi smartphone tidak akan berkembang pesat seperti sekarang kalau tidak ditunjang oleh suatu sistem operasi mobile Android milik perusahaan raksasa google. Android adalah sistem operasi yang dibuat oleh google, sistem operasi ini bersifat open source dan bisa di kembangkan oleh siapapun saja, sistem operasi android dibangun dari sistem operasi linux (http://chapila.com). Android dipenuhi dengan beragam aplikasi berbasis web yang tidak membutuhkan ruang simpan besar. Layanan - layanan berbasis internet seperti email, facebook, twitter, dan layanan jejaring sosial lainnya sangatlah mudah di akses. Karakteristik tersebut menjadi keunggulan Android dalam mengungguli pesaingnya seperti sistem operasi IOS, dan OS. Sehingga sebagaian besar perusahaan -perusahaan produsen smartphone menggunakan sistem Android dalam pengoperasian smartphonenya.

Pengguna ponsel tidak lagi terbatas pada orang-arang yang sudah bekerja yang memiliki daya beli, namun juga pengguna ponsel sudah merambah pada siswa, mahasiswa bahkan anak kecil.

Ponsel atau telepon seluler merupakan salah satu alat komunikasi yang banyak digunakan saat ini, tidak terkecuali mahasiswa. Kini banyak Mahasiswa menggunakan Smartphone terutama smartphone android untuk dijadikan sebagai media untuk mengakses informasi secara mudah dan cepat. Kaum muda dikenal sangat dekat dengan hal -hal yang baru dan salah satunya adalah smartphone android. Smartphone sudah menjadi suatu gaya hidup mereka, dan merupakan atribut yang selalu dibawa dalam pergaulan.

Pengguna smartphone di kalangan mahasiswa amat lah besar sehingga mempunyai potensi pasar yang cukup besar pada segmen ini, maka adalah penting untuk mengetahui alasan -alasan dan persepsi mereka terhadap sebuah produk smarphone sehingga perusahaan dapat mengetahui dengan tepat karakteristik segmen ini, yang pada akhirnya dapat menerapkan strategi yang tepat untuk bisa merebut segmen pasar tersebut.

Berdasarkan uraian di atas, penulis tertarik untuk melakukan penelitian dengan judul " Analisis Segmen Pasar Produk Handphone Berbasis Android di lingkungan mahasiswa di Banjarmasin".

Berdasarkan latarbelakang diatas maka dapat disusun rumusan masalah "Bagaimanakah segmen pasar smartphone berbasis Android berdasarkan atribut produk pada Mahasiswa di Banjarmasin ?"

\section{KAJIAN LITERATUR}

\section{Pengertian Produk}

Produk merupakan titik pusat dari kegiatanpemasaran karena produk merupakan hasil dari suatu kegiatan perusahaan yang dapat ditawarkan kepasar untuk dibeli, digunakan atau dikonsumsi yangtujuannya untuk memuaskan kebutuhan dan keinginan konsumen.

Menurut Kotler dan Amstrong (2015:248) Produk adalah sebagai berikut:"A product as anything that can be offered to a market for attention, acquisition, use or consumption that might satisfy a want or need". John W. Mullins dan Orville C. Walker (2013:252) mendefinisikan produk sebagai berikut:"A product can be defined as anything that satisfies a want or need through use, consumption or acquisition". Berbeda halnya dengan pendapat Stanton yang dikutip oleh Buchari Alma (2013:139) yang mendefinisikan produk sebagai berikut:"A product is a set of tangible and intangible atributes, including packaging, color, price, manufacturer's prestige, and manufacture's retailer which the buyer may accept as offering want".

Berdasarkan beberapa pengertian di atas, diketahui bahwa produk adalah seperangkat atribut yang didalamnya termasuk segala identitas produk yang dapat di tawarkan kepada pasar untuk diperhatikan dan kemudian dimiliki, digunakan atau dikonsumsi guna memuaskan keinginan dan kebutuhan konsumen.Produk menjadi salah satu komponen utama atau yang paling dipertimbangkan dalam sebuah transaksi dipasar.

\section{Dimensi Kualitas Produk}

Kualitas produk adalah karakteristik dari produk dalam kemampuannya untuk memenuhi kebutuhan - kebutuhan yang telah yang telah ditentukan dan mempunyai sifat laten. Menurut Tjiptono (2008), Kualitas Produk adalah perpaduan antara sifat dan karakteristik yang dapat menentukan sejauh mana output (keluaran) dapat memenuhi prasyarat kebutuhan konsumen atau 
menilai sejauhmana sifat dan karakteristik tersebut memenuhi kebutuhan konsumen. Kualitas sebuah produk baik itu sebuah barang maupun jasa ditentukan melalui dimensi-dimensinya. Dimensi tersebut dinamakan dimensi kualitas produk.

Menurut David Garvin, untuk menentukan dimensi kualitas produk, dapat dilakukan melalui 8 dimensi. Ke 8 dimensi tersebut antara lain :

1. Performance

Performance berhubungan dengan aspek fungsional suatu produk dan merupakan sebuah karakteristik utama yang dipertimbangkan konsumen ketika sedang dalam membeli produk tersebut

2. Feature

Featur adalah aspek performansi yang bermanfaat pada untuk menambah fungsi dasar, yang berhubungan dengan pilihan - pilihan produk serta pengembangan produk tersebut.

3. Reliability

Reliability merupakan hal yang berhubungan dengan probabilitas atau kemungkina suatu produk berhasil menjalankan fungsinya setiap kali dipakai atau digunakan dalam periode waktu dan kondisi tertentu.

4. Conformance

Conformance berhubungan dengan tingkat kesesuaian dalam hal spesifikasi yang telah ditetapkan sebelumnya berdasarkan keinginan konsumen. Conformance merefleksikan derajat ketetapan diantara karakteristik desain produk dengan karakteristik kualitas standar yang sudah ditetapkan sebelumnya.

5. Durability

Durability berhubungan dengan tingkat suatu refleksi atas umur ekonomis berapa ukuran daya tahan atau masa pakai suatu produk

6. Serviceability

Serviceability adala karakteristik yang berhubungan dengan kompetensi, kecepatan, akurasi, dan kemudahan dalam memberikan layanan untuk perbaikan suatu produk (barang).

7. Aesthetics

Aesthetics adalah suatu karakteristik yang bersifat subjektif tentang nilai -nilai estetika yang berhubungan dengan pertimbangan pribadi serta refleksi dari preferensi seorang individual.

8. Fit and Finish

Fit and Finish bersifat subjektif, berhubungan dengan perasaan konsumen tentang keberadaan sebuah produk sebagai produk yang berkualitas.

\section{Segmentasi}

Perusahaan akan sangat sulit memasarkan produknya ke pasar yang sifatnya sangat heterogen (kebutuhan dan keinginan pasar sangat bervariasi, berbeda satu sama lain). Oleh karena itu, perusahaan harus membuat pasar menjadi lebih homogen dalam kelompok tertentu yang lebih spesifik, yang disebut segmentasi pasar Segmentasi adalah sebuah metode bagaimana melihat pasar secara kreatif, artinya perusahaan perlu melihat segmentasi sebagai seni mengidentifikasi dan memanfaatkan beragam peluang yg muncul di pasar (Kartajaya,2006). Segmen pasar yang homogen memiliki kesamaan dalam pola dan kebiasaan membeli, cara penggunaan produk, kebutuhan pemakai, motif pembelian, sikap terhadap produk serta memiliki respon yang sama terhadap bauran pemasaran. Segmentasi memungkin perusahaan mendapatkan gambaran yang lebih jelas mengenai peta kompetisi serta menentukan posisi pasar perusahaan. Dalam penelitian ini segmentasi didasarkan atas pesepsi konsumen dan juga persepsi perusahaan terhadap kesamaan dan perbedaan masing-masing merek handphone. Handphone yang mempunyai kemiripan akan dikelompokkan dalam satu segmen, sehingga nantinya akan diketahui siapa pesaing terdekat perusahaan.

\section{Penelitian Terdahulu}

Penelitian terdahulu yang digunakan sebagai bahan referensi, yang berhubungan dengan variabel penelitian ini adalah :

1. Pratama, Novendi dan kawan-kawan (2015), Judul penelitian : Analisis Segmen Pasar Produk Handphone Berbasis Android Berdasarkan Atribut Produk Di Lingkungan Mahasiswa Fakultas Ekonomi Universitas Jember. Hasil penelitian menunjukkan bahwa segmen pasar ponsel berbasis android dikalangan mahasiswa berdasarkan atribut produk di Fakultas Ekonomi Universitas Jember adalah terbentuk menjadi 3 klaster, yaitu:

a. klaster 1 adalah responden yang mementingkan atribut fitur, desain dan jaminan. Agar dapat mencerminkan atributatribut tersebut maka klaster 1 diberi nama "Klaster Produk".

b. Klaster 2 adalah responden yang mementingkan atribut kualtias. Agar dapat mencerminkan atribut-atribut tersebut maka klaster 2 diberi nama "Klaster Kualitas".

c. Klaster 3 adalah responden yang mementingkan atribut harga, kinerja, daya tahan, citra merek, dan kapasitas. Agar dapat mencerminkan atribut-atribut tersebut maka klaster 3 diberi nama "Klaster Keunggulan".

2. Alfian dan Sudaryanto (2015) judul penelitian: Analisis Segmentasi Pasar Produk Rokok Mild Berdasarkan Atribut Produk Di Kabupaten Jember. Hasil penelitian menunjukkan bahwa:

a. Konsumen rokok Mild di Jember terbagi menjadi dua segmen. Segmen 1 (kurang selektif) adalah konsumen yang kurang memperhatikan atribut yang ada pada prokok Mild sementara segmen 2 (selektif) adalah konsumen yang mempertimbangkan atribut produk rokok Mild. 
b. Rokok LA Mild, GG Mild, A Mild, dan Pro Mild memiliki kemiripan dalam posisinya di mata konsumen. Sementara rokok Class Mild memiliki perbedaan dengan keempat jenis rokok Mild tersebut, artinya Class Mild memiliki segmen sendiri pada rokok jenis Mild.

c. Produk rokok Mild yang paling diminati oleh konsumen di Jember adalah LA Mild. Rokok LA Mild dapat diterima oleh mayoritas konsumen di semua segmen.

d. Atribut produk yang membedakan segmen rokok di Jember adalah merek, kemasan, harga, tar dan nikotin, serta aroma. Harga merupakan atribut yang paling membedakan antar segmen rokok Mild di Jember.

3. Ameriana, dan Soetiarso, (2008), judul penelitian "Segmentasi Pasar dan Pemetaan Persepsi Atribut Produk Beberapa Jenis Sayuran Minor (Under-utilized). Hasil penelitian menunjukkan bahwa :

a. Segmen pasar pertama kacang koro/roay adalah konsumen yang menganggap bahwa harga kacang koro/roay tidak mahal, namun cenderung meragukan ketersediaannya di pasar, sedangkan segmen pasar kedua kacang koro/roay adalah konsumen yang setuju bahwa kacang koro/roay rasanya enak serta mudah diperoleh di pasar.

b. Segmen pasar pertama katuk adalah konsumen yang menganggap bahwa harga katuk tidak mahal, namun cenderung meragukan ketersediaannya di pasar, sedangkan segmen pasar kedua katuk adalah konsumen yang setuju bahwa katuk dapat pula berfungsi sebagai obat, rasanya enak serta mudah diperoleh di pasar.

c. Segmen pasar pertama kecipir adalah konsumen yang menganggap bahwa kecipir tidak memiliki atribut fungsi obat dan tidak tahan simpan, sedangkan segmen pasar kedua kecipir adalah konsumen yang setuju bahwa kecipir bergizi tinggi, berfungsi sebagai obat, dan tahan simpan.

d. Segmen pasar pertama labu siam adalah konsumen yang meragukan bahwa labu siam memiliki atribut gizi tinggi, sedangkan segmen pasar kedua labu siam adalah konsumen yang setuju bahwa labu siam memiliki gizi tinggi, dan berfungsi sebagai obat.

\section{METODE PENELITIAN}

Penelitian ini merupakan penelitian yang menggunakan data primer dengan metode survei. Penelitian survei adalah penelitian yang pengambilan data langsung ke lapangan yang dilakukan pada populasi yang besar maupun kecil, tetapi data yang diambil adalah data sampel dari populasi yang dianggap memenuhi syarat untuk dijadikan sampel.

Instrumen penelitian yang digunakan adalah pengumpulan data primer dengan cara menyebarkan kuesioner kepada para responden. Populasi dalam penelitian ini adalah seluruh mahasiswa di Kota Banjarmasin yang memiliki dan menggunakan Handphone berbasis Android. Sampel pada penelitian ini sebanyak 140 responden yang diambil secara acak dari mahasiswa yang ada di Banjarmasin.

Skala pengukuran dalam penelitian ini menggunakan skala likert dengan 5 kategori jawaban yaitu Sangat Penting (SP) dengan skor jawaban 5, Penting (P) dengan skor jawaban 4, Baik (Baik) skor jawaban 3, Tidak Penting (TP) skor jawaban 2, dan Sangat Tidak Penting (ST) skor jawaban 1.

\section{HASIL PENELITIAN DAN PEMBAHASAN}

Langkah awal adalah melakukan Uji Validitas dan Reliabilitas instrumen penelitian yang dilakukandengan menggunakan program SPSS for windows release 22.0. Hasil analisis Validitas dan Reliabilitas disajikan pada Tabel 1.

Tabel 1. Hasil Uji Validitas

\begin{tabular}{lcc}
\hline \multirow{1}{*}{ Variabel } & \multicolumn{2}{c}{ Uji Validitas } \\
\cline { 2 - 3 } & Nilai r hasil & Ket \\
\hline Kualitas & 0,603 & Valid \\
\hline Harga & 0,420 & Valid \\
\hline Kinerja & 0,477 & Valid \\
\hline Daya Tahan & 0,555 & Valid \\
\hline Kehandalan & 0,629 & Valid \\
\hline Citra Merek & 0,574 & Valid \\
\hline Fitur & 0,672 & Valid \\
\hline Desain & 0,679 & Valid \\
\hline Model & 0,701 & Valid \\
\hline Spesifikasi & 0,492 & Valid \\
Produk & & \\
\hline Kafasitas & 0,412 & Valid \\
\hline Garansi & 0,377 & Valid \\
\hline Estetika & 0,650 & Valid \\
\hline
\end{tabular}

Berdasarkan tabel 1, dapat disimpulkan bahwa secara keseluruhan instrumen dari variabel penelitian adalah valid karena memiliki nilai koefesien korelasi $r>0,3$.

Tabel 2. Uji Reliabilitas

\begin{tabular}{lcc}
\hline \multirow{1}{*}{ Variabel } & \multicolumn{2}{c}{ Uji Validitas } \\
\cline { 2 - 3 } & Nilai $\mathbf{r}$ hasil & Ket \\
\hline Kualitas & 0,815 & Reliabel \\
\hline Harga & 0,815 & Reliabel \\
\hline Kinerja & 0,815 & Reliabel \\
\hline
\end{tabular}




\begin{tabular}{lcc}
\hline \hline \multirow{2}{*}{ Variabel } & \multicolumn{2}{c}{ Uji Validitas } \\
\cline { 2 - 3 } & Nilai r hasil & Ket \\
\hline Daya Tahan & 0,815 & Reliabel \\
\hline Kehandalan & 0,815 & Reliabel \\
\hline Citra Merek & 0,815 & Reliabel \\
\hline Fitur & 0,815 & Reliabel \\
\hline Desain & 0,815 & Reliabel \\
\hline Model & 0,815 & Reliabel \\
\hline Spesifikasi & 0,815 & Reliabel \\
Produk & & \\
\hline Kafasitas & 0,815 & Reliabel \\
\hline Garansi & 0,815 & Reliabel \\
\hline Estetika & 0,815 & Reliabel \\
\hline
\end{tabular}

Berdasarkan tabel 2, hasil pengujian reliabilitas menunjukan bahwa seluruh alpha lebih besar dari standar yang sudah ditetapkan, yaitu 0,6 , sehingga dapat disimpulkan semua instrumen dalam penelitian ini adalah reliabel.

Analisis klaster merupakan suatu teknik analisis statistisk yang ditujukan untuk membuat klasifikasi individu - individu atau objek - objek kedalam kelompok - kelompok yang lebih kecil yang berbeda satu dengan yang lain (Umar, 2008:14). Prosedur analisis klaster ini di gunakan untuk mengelompokkan objek (responden, konsumen, produk, dan lain - lain) atau merupakan proses untuk meringkas sejumlah objek menjadi lebih sedikit dan memakan sebagian klaster. Dasar yang pengelompokkan yang di gunakan dalam analisis klaster adalah kesamaan (similarity) atau jarak ketidaksamaan (distance). Metode yang di gunakan untuk membuat klasifikasi dapat di pilih satu dari 2 metode, yaitu memperbarui kelompok kelompok klaster secara iteraktif atau hanya melakukan klasifikasi.

Dalam analisa klaster tidak ada variable bebas dan tergantung karena model analisa ini merupakan independent. Kegunaan utama adalah untuk mengelompokkan obyek - obyek berdasarkan karakteristik tertentu yang sama. Obyek dapat berupa benda, misalnya produk atau orang yang biasa disebut responden. Klaster sebaiknya mempunyai kesamaan yang tinggi dalam kelompok klaster tersebut tetapi mempunyai perbedaan yang besar antar kelompok klaster.

Berdasarkan tujuan penelitian di atas, maka penelitian ini merupakan Cluster dengan metode Kmean cluster. Metode ini di gunakan untuk mengetahui segmen pasar handphone android pada mahasiswa berdasarkan atribut produk. $\mathrm{K}$ - Means Cluster merupakan salah satu prosedur pengelompokkan pada Non Hierarki Cluster. Metode ini bertujuan untuk mengelompokkan obyek sedemikian rupa sehingga jarak tiap - tiap obyek ke pusat kelompok di dalam satu kelompok adalah minimum.

K-Means Cluster merupakan salah satu prosedur pengelompokan pada Non Hierarki 


\begin{tabular}{lccc}
\hline \multicolumn{4}{c}{ Tabel 4. Final Cluster Centers } \\
\cline { 2 - 4 } & \multicolumn{3}{c}{ Cluster } \\
\cline { 2 - 4 } & $\mathbf{1}$ & $\mathbf{2}$ & $\mathbf{3}$ \\
\hline $\mathbf{X 1}$ & 2,0 & 4,8 & 4,7 \\
\hline $\mathbf{X} 2$ & 3,5 & 4,5 & 4,1 \\
\hline $\mathbf{X 3}$ & 3,0 & 4,6 & 4,5 \\
\hline $\mathbf{X} 4$ & 2,8 & 4,8 & 4,7 \\
\hline $\mathbf{X 5}$ & 3,5 & 4,5 & 3,9 \\
\hline $\mathbf{X 6}$ & 3,5 & 4,1 & 3,1 \\
\hline $\mathbf{X} 7$ & 2,8 & 4,6 & 3,9 \\
\hline $\mathbf{X 8}$ & 2,5 & 4,2 & 3,0 \\
\hline $\mathbf{X 9}$ & 3,0 & 4,2 & 3,0 \\
\hline $\mathbf{X 1 0}$ & 2,0 & 4,5 & 4,4 \\
\hline $\mathbf{X 1 1}$ & 4,0 & 4,9 & 4,6 \\
\hline $\mathbf{X 1 2}$ & 3,5 & 4,3 & 4,1 \\
\hline $\mathbf{X 1 3}$ & 2,5 & 4,0 & 3,0 \\
\hline
\end{tabular}

Berdasarkan Tabel Final Cluster Center maka dapat dibagi segmen pasar sebagai berikut:

1. Klaster 1 adalah responden yang mementingkan atribut harga, kinerja, daya tahan, fitur, spesifikasi, dan garansi. Supaya dapat menggambarkan atribut atribut tersebut maka klaster 1 diberi nama "Klaster Kinerja"

2. Klaster 2 adalah responden yang mementingkan semua atribut kecuali garansi. Agar dapat mencerminkan atribut-atribut tersebut maka klaster 2 diberi nama "Klaster Produk".

3. Klaster 3 adalah responden yang mementingkan atribut fitur, model, kapasitas. Agar dapat mencerminkan atribut-atribut tersebut maka klaster 3 diberi nama "Klaster Keunggulan".

Tabel Number of Case in Each Cluster menunjukkan jumlah responden yang masuk dalam klaster1, klaster 2 dan klaster 3.

Tabel 5. Number of Cases in each Cluster

\begin{tabular}{rcc}
\hline Klaster & Jumlah Orang & Persentase (\%) \\
\hline Klaster 1 & 4 & 2,760 \\
\hline Klaster 2 & 82 & 56,55 \\
\hline Klaster 3 & 59 & 40,68 \\
\hline
\end{tabular}

Berdasarkan Tabel 5, number in Case in Each Cluster tampak bahwa jumlah responden terbesar adalah klaster 2 sebanyak 82 orang $(60,70 \%)$, sedangkan jumlah klaster terkecil adalah pada klaster 1 sebanyak 4 responden (2,50\%). Berdasarkan hasil tersebut dapat di nyatakan bahwa responden secara umum menganggap bahwa semua atribut produk pada handphone berbasis Android adalah penting.

\section{PENUTUP}

Berdasarkan hasil penelitian dapat dijelaskan bahwa pengguna handphone android dikalangan mahasiswa di Banjarmasin dapat dikelompokkan menjadi 3 segmen, dan rata-rata responden menyatakan bahwa semua atribut produk pada hanphone android adalah penting, hal ini terlihat pada tabel final cluster center yang semuanya bernilai positif $(+)$. oleh karena itu bagi perusahaan produsen handphone android sebaiknya selalu memperhatikan dan terus menerus melakukan inovasi dan pengembangan produk khususnya variabel dari atribut produk karena variabel variabel tersebut menurut pengguna dianggap penting.

Berdasarkan analisis dan pembahasan maka dapat ditarik kesimpulan segmen pasar ponsel berbasis Android pada mahasiswa di Banjarmasin adalah sebagai berikut :

1. Klaster 1 adalah responden yang mementingkan atribut harga, kinerja, daya tahan, fitur, spesifikasi, dan garansi. Klaster ini diberi nama "Klaster Kinerja"

2. Klaster 2 adalah responden yang mementingkan semua atribut kecuali garansi. Klaster ini diberi nama "Klaster Produk".

3. Klaster 3 adalah responden yang mementingkan atribut fitur, model, kapasitas. Klaster ini diberi nama "Klaster Keunggulan."

Adapun saran penelitian ini adalah sebagai berikut :

1. Peneliti yang akan datang hendaknya objeknya tidak hanya mahasiswa namun juga pengguna ponsel android secara umum.

2. Peneliti yang akan datang sebaiknya menggunakan Sampel yang lebih besar sehingga data yang diperoleh akan lebih baik.

3. Dalam menetapkan segmen hendaknya tidak hanya mempertimbangkan variabel atribut produk namun variabel lain seperti demografis, geografis dan psikologis.

\section{DAFTAR PUSTAKA}

Alfian dan Sudaryanto, 2015. Analisis Segmentasi Pasar Produk Rokok Mild Berdasarkan Atribut Produk Di Kabupaten Jember.

Alma, Buchari, 2014. Manajemen Pemasaran dan Pemasaran Jasa. Bandung: Alfabeta.

Ameriana, dan Soetiarso, 2008.Segmentasi Pasar dan Pemetaan Persepsi Atribut Produk Beberapa Jenis Sayuran Minor (Underutilized).

Armstrong, Kotler 2015, "Marketing an IntroducingPrentice Hall twelfth edition", England : Pearson Education, Inc

Ghozali, Imam, 2005, Aplikasi Multivariate Dengan Program SPSS, Badan Penerbit Diponegoro.

Kartajaya, Hermawan, 2002. Hermawan Kartajaya On Marketing. Jakarta : PT Gramedia Pustaka Utama. 
Kotler, Philip, dan Amstrong, Gary, 2001, Dasardasar Pemasaran, Jilid Satu, Edisi Kesembilan, Penerbit PT. Gramedia Pustaka Utama : Jakarta

Kotler, Philip dan Keller, Kevin Lane, 2008, Manajemen Pemasaran. Edisi Kedua Belas Jilid 1, Penerbit PT. Indeks, Jakarta

Kotler, Philip; Armstrong, Garry, 2008. Prinsip prinsip Pemasaran, Jilid 1, Erlangga, Jakarta.

Mullins, John W dan Walker Jr, Orville C. 2013.Marketing Management: A Strategic Decision-Making Approach, 8th Edition, McGraw-Hill International Edition.

Pratama, Novendi dan kawan-kawan(2015). Analisis Segmen Pasar Produk Handphone Berbasis Android Berdasarkan Atribut Produk Di Lingkungan Mahasiswa Fakultas Ekonomi Universitas Jember.

Tjiptono, Fandy. 2008. Strategi Pemasaran, Edisi Ketiga. Andi, Yogyakarta

Tribunnews.com, 2019. Benarkah Smartphone Sudah Jadi Kebutuhan Dasar Manusia? Ternyata Ini Jawabannya,Diakses tanggal 03-08-2019,https://www.tribunnews.com/ techno/2018/08/14/benarkah-smartphonesudah-jadi-kebutuhan-dasar-manusiaternyata-ini-jawabannya.
Tjiptono, Fandy, 2008, Strategi Pemasaran, Edisi 3, ANDI: Yogyakarta.

Sugiyono, 2008, Metode Penelitian Bisnis, Cetakan Keduabelas, Penerbit Alfabeta Bandung.

\section{$\underline{\text { Profil penulis }}$}

1. Abul Hasan Asy'ari, S.E., M.M., Keilmuan Manajemen, Sekolah Tinggi Ilmu Ekonomi (STIE) Pancasetia Banjarmasin,

2. Dr. Arief Noviarakhman Zagladi, S.E., M.M., Keilmuan Manajemen, Sekolah Tinggi Ilmu Ekonomi (STIE) Pancasetia Banjarmasin, Jl. Ahmad Yani, Km.5,5 Banjarmasin - 70248

Email: a_zagladi@yahoo.com 